\title{
The World Map of Major Active Faults Project
}

\author{
Vladimir G. Trifonov $\left.{ }^{1}\right)$ and Michael N. Machette $\left({ }^{2}\right)$ \\ (') Geological Institute, Moscow, Russia \\ $\left.{ }^{2}\right)$ U.S. Geological Survey, Denver, CO, U.S.A.
}

\begin{abstract}
The «World Map of Major Active Faults» (International Lithosphere Program Project II-2) will assemble important geological and paleoseismological data on regional, continental, and global scales for the new Global Seismic Hazards Assessment Program. By 1995, we hope to produce two main types of products: a series of modern digital maps showing the location, age, and activity rates of major earthquake-related features (such as faults, fault-related folds, and volcanic features) and a catalogue of data relating to these features. Together these products will represent one of three key International Lithosphere Program contributions to GSHAP, the other two being the World Stress Map (Project II-1) and Paleoseismology of the Late Holocene (Project II-3).
\end{abstract}

\section{Introduction}

Faults with historic, Holocene $(<10 \mathrm{ka}$ (kilo annum)), and late Pleistocene (the past $100-130 \mathrm{ka})$ manifestations of activity are herein defined as active faults. In general, about 90 percent of the historic strong earthquakes have occurred on active fault zones; however, only a small fraction of active fault zones have seismic activity. This later relation occurs because recurrence intervals on slow slip-rate faults $(<1 \mathrm{~mm} / \mathrm{yr})$ are typically measured in thousands to tens of thousands of years whereas the seismic record is only hundreds to thousands of years long. Therefore, the identification, analysis, and mapping of all active faults is a very important element of seismic zonation and other seismotectonic studies as they apply to the new Global Seismic Hazard Assessment Program (GSHAP). In addition, active faults are often associated with other geological hazards (volcanism, fluid and gas activity, hydrogeological changes, karst, landslides, and erosion), and their study is pertinent to understanding broader scale recent and ancient geodynamics. The im- portance of accurate portrayals of active faulting, both on regional and worldwide scales, led us to propose that a World Map of Major Active Faults be compiled. In 1989, this activity was initiated as Project II-2 of the International Lithosphere Program (ILP) and now serves as a keystone contribution to the new GSHAP under the auspices of the International Decade for Natural Disaster Reduction (IDNDR). Our project is one of three key ILP contributions to GSHAP, the other two being the World Stress Map (Project II-1, see Zoback, this volume) and Paleoseismology of the late Holocene (Project II-3, see Pantosti and Yeats, this volume).

This project involves more than 60 scientists from 37 countries and is open for wider cooperation in the next few years. In 1992, the Project was subdivided into Eastern and Western Hemisphere parts and an Oceanic part for better coordination. V.G. Trifonov (Russia) leads the Eastern Hemisphere part and serves as chairman and general coordinator of the Project. The Western Hemisphere part is led by M.N. Machette (U.S.A.) and the Oceanic part is led by G.B. Udintsev (Russia). 
Active faults that will be shown on the maps have been identified and differentiated using geological and geomorphological techniques, remote-sensing data, and correlation with existing seismological, geophysical, geodetic, hydrogeological, geochemical, archaeological, and historical data. This combination of data not only permits one to identify active faults and determine their structural and kinematic parameters, but also to 1) characterize regimes of recent crustal motion, 2) estimate some parameters of potential earthquakes, 3) better understand the relations between mechanical properties of rocks and recent crustal motions, and 4) identify hazards posed by currently aseismic but active fault zones.

The most evident manifestations of active faulting are 1) offsets of young topographic, geologic, or cultural features, 2) recent and prehistoric seismic ruptures, 3) chains of hypocenters of earthquakes, and 4) recent displacement (creep) recorded by repeated geodetic measurements. Detection of active faulting requires specialized ground observations and (or) analysis of detailed remote-sensing data. In most regions of the world, these types of observations and analyses are not common, or have attracted the attention of specialists only during the past several decades. Because of these advances in fault mapping techniques, the scale and number of studies are quite variable from country to country and from continent to continent. Obviously, the more robust data sets are associated with developed countries that have had surface faulting events in the past few decades.

\section{Maps of active faults and data catalogues}

The purposes of Project II-2 are to compile the world map at a scale of $1: 10 \mathrm{M}$ and the maps of continents (or regions) at scales of $1: 5 \mathrm{M}$ by the end of 1995 . The maps will be accompanied by explanatory notes (map explanation) and a separate catalogue (fault data base) describing pertinent data for major active faults will be issued. All data, including the detailed geometry of the fault lines, will be compiled on personal-computer and workstation platforms.

In our map explanations (see Appendix), all faults are differentiated by intensity of tectonic movements (i.e., slip rate), age of last manifestations of fault activity, sense of displacement, and reliability of identification. Manifestations of young folding, location of Holocene volcanoes, and epicenters of larger recent earthquakes (differentiated by magnitude and hypocentral depth) might also be shown as they may reflect tectonic activity not manifested at the surface.

The largest reasonable scale that one might use to compile the United States, Japan, and other areas of detailed mapping is probably $1: 250 \mathrm{~K}\left(1^{\circ} \times 2^{\circ}\right.$ sheet $)$. This scale would allow eventual out-put for states, provinces, or small countries at map scales of $1: 500 \mathrm{~K}$ to $1: 1 \mathrm{M}$ without serious loss of information. Maps at 1:250K scale are commonly available, are near the maximum size of digitizing tables commonly used with personal computers, and have been used for much of the Quaternary fault compilations of the Western U.S. However, some countries do not have adequate topographic base maps at these scales, in which case we will digitize the fault information at national scales (commonly $1: 1 \mathrm{M}$ or smaller). Most previous regional compilations have been at scales of as small as $1: 2.5 \mathrm{M}$, which are inadequate to describe all but the major faults in a region. In addition to fault location and style, our maps will show age of last movement and slip rate (as a proxy for fault activity where recurrence intervals are unknown). Our scheme allows some flexibility for age differentiation of faults between regions and continents owing to the differing levels of investigation and abilities to date prehistoric faulting events.

As many as five divisions of ages of last movement will be depicted on the Active Fault Maps (table I), and a lesser number of divisions will be used for areas where extensive or detailed paleoseismic data does not exist. Because age control is poorly established in many regions, we allow flexibility in making the age divisions. For example, if a fault is known to be younger than $100-130 \mathrm{ka}$ (late 


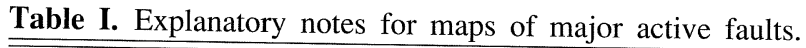

ACTIVE FAULTS - Differentiated by rates of fault movement (slip rate):

$-\geq 5 \mathrm{~mm} / \mathrm{yr}$
$-\quad<5$ to $>1 \mathrm{~mm} / \mathrm{yr}$
$-\quad \leq 1 \mathrm{~mm} / \mathrm{yr}$
Plate boundary faults and subduction zones.

Lesser strike-slip and major extensional faults.

Most extensional and intraplate faults. Faults with unknown rates probably are in slower categories.

Age of last fault activity (usually surface rupturing or uplift event):
Historic $(<200$ to $<2000 \mathrm{yr}$, red)
Holocene $(<10 \mathrm{ka}$, orange)
Late Quaternary $(<100$ to $130 \mathrm{ka}$, green)
Late or middle Quaternary $(<700$ to $730 \mathrm{ka}$, blue)
Quaternary ( $<1.6 \mathrm{Ma}$, black) lower boundaries for the third and fourth groups can vary from region to region. These differences will be shown graphically in the final map explanation. Color scheme is preliminary.
The historical period varies from region to region, and the

Sense of displacements and reliability of fault identification:

\footnotetext{
Thrusts and reverse faults

$\Longrightarrow$ Stike-slip faults

$\perp \perp$ Normal faults

Extensional faults

- Faults with unknown sense of slip

- Surficial continuations of deep-seated seismotectonic zones

$\cdots$ Buried, deep-seated fault zones

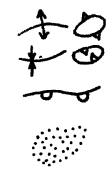

Anticlines

Synclines

Flexures (monoclines)

Areas of strong liquefaction related to earthquakes on blind or concealed faults
}

YOUNG FOLDS AND OTHER FEATURES - Differentiated by age (same colors as faults): on the right.
Identification: reliable faults are shown on the left side (solid) and inferred faults (dashed) are shown on the right.

Last two symbols only appear in oceanic areas.

Many young folds are related to blind thrust faults. Linear features are shown on the left and isometric features

Some strong earthquakes, such as 1811-12 New Madrid earthquakes, produced liquefaction features but no documented surface ruptures.

\section{YOUNG VOLCANISM AND OTHER SIGNS OF ACTIVITY:}

\section{* Volcanoes \\ $\oplus$ Areas of hydrothermal activity}

\section{EARTHQUAKE EPICENTERS - Differentiated by:}

Magnitude:

$$
\begin{array}{ll}
\text { O } & \text { M } 4 \text { to }<6 \\
\mathrm{O} & 6 \text { to }<7 \\
\mathrm{O} & \mathrm{M} \text { to }<8 \\
\mathrm{M} \geq 8
\end{array}
$$

Active (Holocene, red) and late Quaternary (orange).

Shown at the map scale on the left and at considerably less than map scale on the right.

Time of earthquake:

$$
\begin{array}{ll}
\text { O } & \text { Post-1950 } \\
\oslash & \text { Pre-1950 } \\
\otimes & \text { Prehistoric }
\end{array}
$$

Earthquake epicenter data will be shown at the discretion of authors on a regional or continental basis, using established earthquake catalogues. Depths will be shown by color: $<70 \mathrm{~km}$ (red), 70-300 km (blue), and $>300 \mathrm{~km}$ (black). Color scheme is preliminary. Note: active faults in some regions may be represented differently in terms of ages and features shown owing to varying
stratigraphic, radiometric or geomorphic control. 
Pleistocene), but could be Holocene ( $<10 \mathrm{ka})$, we would show the fault as late Quaternary $(<100$ to $<130 \mathrm{ka})$. Historic events are indicated by the date of most recent faulting (i.e., 1906). Three ranges of slip rates, depicted by fault line thickness (table I), will be used on the Active Fault Maps in order to differentiate rates of activity. In order to provide a basis for regional and global comparison of fault activity and geologically based determinations of seismic hazard, the catalogue (data base) should contain available information on the principles, methods, or techniques for detecting active faults, regional descriptions of the faults and other manifestations of active tectonics, and general characteristics of recent tectonics and geodynamics.

If evidence of segmentation (abrupt alongstrike changes in fault characteristics) exists for major faults, these data are also compiled. Because not all parameters are known for each fault, the catalogue will be an incomplete but representative portrayal of paleoseismic data. Information on the following basic parameters will be compiled when available (also see expanded listing in Appendix):

1) number and name;

2) geographic coordinates of the fault (only its ends and principal points in the catalogue);

3) average strike;

4) dip at surface (for points or segments of the fault with the coordinates) or in subsurface;

5) length $(\mathrm{km})$;

6) sense of slip;

7) faulted layers of the lithosphere;

8) age of the last manifestations of activity;

9) signs of fault activity (mainly geomorphic);

10) magnitudes of vertical and lateral offsets during indicated time interval (for points or segments of the fault with the coordinates);

11) rates of motion (total and of different components of motion);

12) seismic manifestations, especially for recent faulting;

13) other activity (exogenous, geophysical, gas, hydrothermal, hydrogeochemical, volcanic, etc.);

14) reliability of data;

15) author(s) of the interpretation and appropriate references.

\section{Eastern Hemisphere}

At this time, most of the basic data have been collected and compiled for the Asian portion of the Eastern Hemisphere, whereas our efforts in Indonesia, Africa and Europe are less complete (see ILP project summary in Berry, 1992). The most detailed and systematic studies of active faults have been carried out in the former USSR, China, Japan, New Zealand, Iran, Syria, Israel, Turkey, Greece, and Iceland. High-quality data also exist for Italy, Portugal, Algeria, the Rhein graben system, Iraq, Pakistan, Northern India, Mongolia, Vietnam, and the Philippines. Individual active fault zones have been described in Scandinavia and sone other parts of Europe, Australia, Indonesia and Afghanistan, and lesser data exists about fault activity in the Great African fault zone from Mozambique to Ethiopia. Studies of active tectonics in other regions, especially in Africa, have been very limited - a situation that is not likely to improve over the duration of the project.

Special difficulties exists in the study of active faults of the continental platform areas because of slow rates of tectonism and sparse evidence of surface faulting. We have overcome this difficulty, partly, by extending our data base back to include fault activity during the middle Pleistocene (700-100 ka) or Quaternary $(<1.6 \mathrm{Ma})$.

The most important result of Project II-2 sponsored studies in the Eastern Hemisphere has been an elaboration of methods and techniques of detection of major active faults and of estimation of their seismic potential. In addition, these techniques have been adapted for different geological and environmental situations. The specific results from these regions have been numerous and can only be mentioned partly in this overview paper. Of particular interest are some generalizations about 
tectonic styles in various regions of the Eastern Hemisphere.

Studies in the region of interaction of the Arabian and the Eurasian plates show that the northern drift of the Arabian plate causes 1) the western motion of Anatolia (and the extension of the Aegean basin as a result, 2) the compression of the Lesser Caucasus arc producing thrusting in the southern slope of the Great Caucasus, and 3) strike-slip faulting in the arc itself and eastward into Iran. Some of the structural peculiarities of the highly seismic Erzincan region and adjacent area are associated with the intersection of the North Anatolian and the East Anatolian fault zones.

As has been shown by Chinese, American, and Russian scientists, the northern drift of the Indian plate in the late Cenozoic is not limited to just underthrusting and deformation of the Southern Tibet, but also produces a profound amount of thrust and strike-slip faulting across a large part of more Northern China, Mongolia, the former Soviet Central Asia, and Southern Siberia. Here, as well as in a majority of the other mobile belts of Asia, the strike-slip component of fault displacement predominates over the vertical component. Rapid and profound amounts of deformation are typical for the upper crust along the Pacific coast of Asia (Kamchatka, Japan, Philippines) and New Zealand.

There seems to be two types of relations between active faults and seismicity. The first type of active faults do not generate earthquakes themselves, but seismic destruction and associated natural and technogeneous disasters are concentrated along such fault zones. The second type of active faults are direct or indirect manifestations of deep-seated zones which generate earthquakes. These earthquakes have maximum magnitudes and recurrence intervals that depend on fault parameters, mechanical properties of rocks, and peculiarities of the stress field in the fault zone. Active faults with impulse, creep, and impulse-creep styles can be identified. The impulse-style faults (stick-slip faults of the Western Hemisphere) have rapid slip during rare strong earthquakes with essentially no movement between the impulses (faulting events). The creep style has continuous movement at variable rates, combined with frequent weak and relatively rare moderate earthquakes. The impulse-creep style is a combination of both styles of motion. Thus, by studying the modern and prehistoric movement history of active fault zones, one can determine the faults style of motion, find signs of old strong (paleo) earthquakes, and estimate their recurrence interval. All these paleoseismic data are important contributions to the Global Seismic Hazards Assessment Program.

\section{Western Hemisphere}

The United States and North American map contributions to the World Map of the Active Faults were woefully nonexistent when Machette assumed responsibility for this region in January 1992. The last comprehensive map of active faults in the Unites States was compiled by Howard et al. (1977) at a scale of 1:5M (and smaller) and based on data collected in 1975. In the interventing 17 years, a potentially large catalogue of paleoseismological data has been generated in the U.S. ILP Project II-2 had planned on using the Geological Society of America Decade of North American Geology (DNAG) Neotectonics Map as a source of data. However, the DNAG project was not completed by the 1991 deadline and was abandoned. Therefore, no systematic collection of data currently exists for U.S. nor its neighboring countries (Canada and Mexico). Thus, any effort to summarize the state of affairs concerning active faulting in North (and South) America in this brief report would be premature. Instead, we report on the status of studies of active faulting in various regions in the Western Hemisphere.

Our effort to compile the North, Central and South America maps is starting anew, with a carefully chosen list of participants. Technical experts from these regions will be selected from known productive experts with strong national contacts. For the United States, the compilation will be done by the USGS in Denver, under the direction of Machette. Given the limited time to produce the North 
American map (two to three years at the most), some goals of the project were revised in late 1991 and a decision was made to limit the data acquisition to just those elements needed for the Global Seismic Hazards Assessment Program (GSHAP).

There are three main elements to assembling a fault map and data base for the United States (and North and South America as well). The first involves general supervision and interpretation of geologic/tectonic information. The second aspect is data entry for the fault catalogue (data base design and management), and the third aspect is the transfer or digitization of fault traces and file identification.

\subsection{The map of major active faults}

The map of the United States (and probably North America) will be compiled and digitized at $1: 250 \mathrm{~K}$ scale, which is the smallest scale at which reasonable state-scale maps can be produced. The compilations of Central and South America active faults will probably be based on less detailed maps, perhaps as small as national scale maps. The traces of five age categories of faults in three slip-rate categories will be portrayed in color using Geographic Information System (GIS) digitalmap-preparation techniques. Although the maps produced for the Eastern Hemisphere are being prepared with IBM-compatible (*) personal computers and scanners using Russian software, we will be using ARC Info on a UNIX-platform for the map preparation. ARC Info is a rather sophisticated GIS system that allows us to change projections, scales, and attributes of features (such as line type, color, and thickness) easily, and to export the graphics files in PICT format for use on personal-computer systems. The publishing scale of the U.S. map will probably be about $1: 2.5 \mathrm{M}$ and the North American map will be $1: 5 \mathrm{M}$, whereas the global map will be at $1: 10 \mathrm{M}$ scale.

\subsection{The catalogue (computer data base)}

Fault data in catalogue form is relatively sparse in the United States, and rare in the other regions of the Western Hemisphere. In the U.S., the state of Utah will soon publish an exellent catalogue by S. Hecker (USGS), and M. Clark (USGS) continues to compile a catalogue of slip-rate data for California. A decade ago, I. Witkind (USGS) published data for four Rocky Mountains states, but these will have to be updated. Overall, we suspect that there are catalogue data for about 20 percent of U.S. faults.

Our strategy is to develop a large body of data on the Quaternary faults (name, location, lengths, segments, age, slip rates, references, etc.) in the U.S. portion of North America. We are currently compiling this data in a word-processing program (Microsoft Word), but plan to import the data to a relational data base (FoxBase) on the Macintosh computer. FoxBase allows us to build vastly different size files for faults that can be exported in report form with variable and long field sizes. Also, FoxBase has strong search capabilities, which should allow us to produce a more user-friendly product. However, we do not expect that most users will have access to Macintosh personal computers, so we also plan to supply the data base to DOS PC-users using FoxBase's laterally equivalent software (FoxPro). The use of a personal-computer data base manager will allow users to search the data set by specific or multiple parameters; for example, find and list all faults with strike-slip faults with historic movement in a certain area. Additionally, we hope to write the data base, a run-time version of the data base program, and the digital map files to CD-ROM for easy access at low user cost.

The status of data for faults (and folds and associated structures) in different regions of the United States is described below (see also table II). This area will comprise about 75 percent of our efforts in the Western Hemisphere owing to the large and robust data set.

(*) The use of brand names in this report does not indicate endorsement by the U.S. Geological Survey or the Department of Interior. 
Table II. Status of Quaternary fault data in the United States.

\begin{tabular}{|c|c|c|c|}
\hline State/region & Regional map & Data base type & Main contacts \\
\hline Alaska & A. Digital, 1992 & A. Text, unpublished & Plafker \\
\hline Washington & B. Compiled, 1991 & C. Uncompiled & Walsh \\
\hline Oregon & B. Part digital, 1992 & B. Partial; text, 1992 & Weldon, Pezzopane \\
\hline California & A. Recompiled, 1992 & B. Partial; text, 1984 & CDMG, USGS \\
\hline Nevada & A. Digital, 1991 & C. Uncompiled & Dohrenwend \\
\hline Idaho & C. Uncompiled & C. Uncompiled & Haller \\
\hline Montana & B. Part digital, 1992 & C. Uncompiled & Stickney \\
\hline Utah & A. Digital, 1992 & A. R-base, 1992 & Hecker \\
\hline Arizona & B. Nondigital, ca. 1987 & B. Partial; text, ca. 1987 & Pearthree \\
\hline New Mexico & B. Part digital, ca. 1987 & B. Partial; text, ca. 1987 & Machette \\
\hline Colorado & B. Digital, ca. 1987 & B. Partial; text, ca. 1987 & Colman, Kirkham \\
\hline Texas & B. Nondigital, 1992 & C. Uncompiled & Collins \\
\hline Mid-Continent & C. Uncompiled & C. Uncompiled & Crone, Obermeier \\
\hline Eastern U.S. & C. Uncompiled & C. Uncompiled & Prowell, Talwani \\
\hline
\end{tabular}

Quality: $\boldsymbol{A}=$ good; $\boldsymbol{B}=$ adequate; $\boldsymbol{C}=$ poor or nonexistent.

Although few formal contacts have been made with technical experts, we have been assembling data for the Western U.S. and developing strategies to test both preparation of the GIS map and the computer data base. Status reports for Central and South America await the outcome of the GSHAP financing and delineation of regional centers and personnel. Once this is done, contacts will be established and responsabilities assigned through regional coordinating centers. Nevertheless, plans are proceeding with a regional planning meeting for the South American map in Quito, Ecuador in early 1993, utilizing a group of researchers interested in Neotectonics of the Andean Cordillera.

\subsection{Status of data for active fault maps}

Alaska. G. Plaffker (USGS) has been assembling data for Alaska during the past 10 years and his new digital map will soon be published by the Geological Society of America. The state contains a large number of active and important faults with relatively high slip rates, although there is little data about recurrence intervals and times of most recent movement. Nevertheless, we are in pretty good shape in terms of map data. Plafker's data base is a text document that will require modest reformatting.

California. California will be the toughest state because it has about one-third of all the faults in the United States. The new California Division of Mines and Geology (CDMG) state map $(1: 750 \mathrm{~K})$, which was released in September 1992, is an appropriate base because it provides a systematic and comprehensive treatment of the data. Previous digital scans of the 1975 map are available, but little effort has been put into tagging files for a GIS application. We have made preliminary arrangements with the CDMG to digitize the new map in late 1992. This cooperative agreement will benefit both parties: ILP will get the latest data for California and the CDMG will have access to a digital map and data set. Having a single compiler for California will be a big advantage and will avoid infighting, but we plan to have regional experts (CDMG, USGS, Universities, etc.) add data that might be unpublished or have been neglected. M. Clark (USGS) and associates have a comprehensive listing (table) of slip-rate data that is about 8 
years old now, but they plan to update the listing in the near future. If the information becomes available, it will be incorporated in our map and data base.

Other West Coast States. R. Weldon and S. Pezzopane (University of Oregon) have a preliminary compilation of Quaternary faults in Central and Eastern Oregon that they plan to issue as a USGS Open-File Report. Researchers at the USGS and Oregon State University can supply data for the western, coastal, and offshore sections of Oregon. The map for Washington will be a larger task to organize. A large amount of well focused research is being conducted in the Seattle and coastal regions of Washington for the National Earthquake Hazards Research Program (NEHRP), which issued a preliminary regional map of seismotectonics (1991) but little integrated data exists for the central and eastern part of the state. The Bureau of Reclamation has prepared several reports for sites in this region.

Rocky Mountains. New mapping is available for Wyoming (Bureau of Reclamation, and Geomatrix) and the Wyoming Geological Survey (WGS) has released a map and textbased fault data file for the state. There is a 1987 version of the Colorado map in digital form (C. Colman, USGS) which shuold be adequate, although a literature search is required for the data base. No regional compilation has been made for Idaho, but past USGS work in the state puts us on good ground. K. Haller (USGS) will compile and digitize the Idaho map and assemble a fault data base for this state. The Montana Bureau of Mines and Geology has compiled several regional maps of Western Montana, but M. Stickney's map of late Quaternary faults will be the most useful product.

Rio Grande rift. About half of New Mexico was digitized by Machette in the 1980's, so the remainder of the state needs to be compiled and a data base needs to be built from the literature. There have been several fault specific studies (Bureau of Reclamation, USGS) and a large effort is on-going at the
Los Alamos National Laboratory (1992-95). The western part of Texas has been studied for the siting of low-level toxic wastes. The Texas Bureau of Geology has a considerable amount of regional data and some site-specific data.

Canada. Most of the active faulting in Canada is associated with the Cordillera (Rocky Mountains), Coast Ranges, and Cascadia subduction zone. However, few detailed maps exist for the land portion of this area. East of the Rocky Mountains, the fault activity lessens markedly and most surface faults are associated with post-glacial rebound from the retreat of the Laurentide ice cap in latest Pleistocene and early Holocene time. One notable exception is the 1989 Ungava earthquake, which produced the first historic intraplate surface faulting on the North American Continent. Adams and other will supply information about this and other cratonic faults in Canada, whereas we hope to engage G. Rogers and J. Clague for the western portion of Canada.

Central America and Caribbean region. The best starting point for a Central American map probably will be the Geologic-Tectonic map of the Caribbean region by Case and Holcombe (1980). Although this map shows tectonic features (ages unspecified, generally post late Cretaceous), there are several excellent summary papers in the GSA DNAG Volume H (Dengo and Case, 1990) and in the GSA Memoir 162 (Bonini et al., 1984), which can help supplement the map. The compilation of Neotectonic faults by Mann et al. (1990) will be the seed for the Central American data base. In addition, we hope to enlist Paul Mann (Texas) and Gabriel Dengo (Guatemala) as regional coordinators, each of whom has a broad knowledge of Caribbean and Central American tectonics. The most studied area seems to be the Baja California and some of the active faults in Guatemala, as a result of investigations by both Central American and U.S. scientists. Additionally, we will try to enlist national representatives to compile data for both the map and catalogue. By early 
1993, we hope to have begun the compilation of Central American and the Caribbean region. At the time this report was written (October 1992), we had identified the following people as potential participants or cooperators:

Mexico: M. Suter (Arizona), O. Quintero (Inst. de Geologia-UNAM), F. Suarez (Cen. de Inv. Cientifica, Ensenada), J. Gonzalez (CICESE, Ensenada), G. Suarez (Inst. de Geofisica-UNAM, Mexico City), M. Ortiz (Inst. de Geografia-UNAM, Mexico City), C. Henry (Univ. of Texas, Austin), T. Rockwell (San Diego);

Costa Rica: S. Mora, G. Alvardo, and R. Barquero (ICE), W. Montero (Univ. de Costa Rica, San Jose), F. Guendel (Univ. Nacional de Costa Rica, Heredia), T. Bullard (Geomatrix), S. Wells (UC-Riverside), T. Gardner (Penn. State);

Guatemala: G. Dengo (Cent. Est. Geol. de Amer. Central), D. Schwartz and G. Plaffker (USGS);

Hispanola: C. Prentise (USGS), P. Mann (Univ. Texas);

Honduras: H. Aveleallemant (Rice);

Nicaragua: G. Plaffker (USGS);

Puerto Rico: W. McCann (Univ. of Puerto Rico), C. Moya (Dept. Nat. Resources, Puerto Ri$\mathrm{co})$.

South America. In January 1992, Machette met with a group of South American researchers interested in Neotectonics of the Andean Cordillera. At this meeting, he proposed that H. Bastias (Argentina) lead an effort to produce a modern active fault map of South America. Although the idea met some initial resistence owing to shortages of manpower and equipment, the group plans to meet in early 1993 to start compilation of such a map. Support for this meeting is being provided through the Western Hemisphere part of ILP project II-2. In addition to the South American participants, we hope to involve European scientists who have been active in the Cordillera as well as interested scientists working in stable areas of the craton (such as Brazil). We will try to coordinate our efforts with CERESIS, which has a long-standing interest in
South American seismology and tectonics. At the present time, the future location and administration of CERESIS is undecided, but we have identified the following scientists as potential participants:

Argentina: H. Bastias and C. Costa (Univ. Nacional de San Juan);

Bolivia: M. Sebrier (Univ. de Paris-Sud, France);

Chile: R. Armijo (Institute de Physique de Globe de Paris, France), I. Dalziel (Univ. of Texas, USA), R. Thiele and F. Herve (Univ. de Chile, Santiago), J. Naranjo (Chilean Geol. Survey, Santiago), Y. Ota (Yokohamà Univ., Japan), B. Atwater, A. Nelson, G. Plaffker (USGS);

Colombia: G. Paris (INGEOMINAS, Cali), H. Diederix (ITC, Netherlands), J. Naranjo (Univ. de Caldas, Manizales);

Ecuador: H. Yepes and P. Hall (Escuela Politechnica Nacional, Quito);

Peru: J. Machare (Inst. Geofisico del Peru, Lima), M. Sebrier (Univ. de Paris-Sud, France);

Venezuela: C. Schubert (Inst. Vene. de Inv. Cientificas), C. Giraldo (CORPOVEN, Caracas), A. Singer (Funvisis), C. Ferrer (Univ. de Los Andes, Merida).

\section{REFERENCES}

BerRy, M.J. (1992): International Lithosphere Program Annual Rep. 1991, Inter-Union Comm. on the Lithosphere Rep. 15, Ottawa, Canada, p. 112.

Bonini, W.E., R.B. Hargraves and R. Shagam (Editors) (1984): The Caribbean-South American plate boundary and regional tectonics, Geological Survey of America Memoir 162, pp. 421.

CAse, J.E. and T.L. Holcombe (1980): Geologic-tectonic map of the Caribbean region, U.S. Geol. Surv. Misc. Inv. Map I-1100, 1 pl. (scale 1:2.5M).

Dengo, G. and J.E. CASE (Editors) (1990): The Caribbean region, in The Geology of North America, Geological Survey of America, Boulder, Colo., pp. 528.

HowARD, K.A. et al. (1977): Preliminary map of young faults in the United States, U.S. Geol. Surv. Misc. Field Studies Map MF-915, 2 pl. (scales 1:5M and 1:7.5M).

Mann, P., C. Schubert and K. Burke (1990): Review of Caribbean neotectonics, in The Geology of North America, The Caribbean region, edited by G. Dengo and J.E. Case, vol. H, Geological Survey of America, Boulder, Colo., pp. 307-338. 
Appendix. Types of data to be compiled in the catalogue of major active faults of the world.

(1) Number and name (several names may be referenced).

$\left(2^{*}\right) \quad$ Geometry of the fault line or the projection of buried fault to the land surface by the geographic coordinates. In the catalogue, only ends and points, where fault parameters change, must be presented. In the data base, all points characteristic for the fault line geometry will be digitized.

(3*) Strike (average for the fault or its segments).

(4) Dip with the coordinates of point (p) or segment (s) where the data were found. For example:

$70^{\circ} \mathrm{NE}:$ p $40^{\circ} 45^{\prime} 07^{\prime \prime} \mathrm{N} ., 45^{\circ} 20^{\prime} 30^{\prime \prime} \mathrm{E}$, at surface, or

$50^{\circ} \mathrm{NW}$ : s $40^{\circ} 45^{\prime} 07^{\prime \prime}$ N., $45^{\circ} 30^{\prime} 40^{\prime \prime}$ E. to $40^{\circ} 29^{\prime} 40^{\prime \prime}$ N., $45^{\circ} 40^{\prime} 00^{\prime \prime}$ E., $0-10 \mathrm{~km}$.

(5*) Length, in $\mathrm{km}$.

(6) Sense of slip (by symbol):

T-Thrust (not steeper than $45^{\circ}$ )

R-Reverse fault (steeper than $45^{\circ}$ )

D-Dextral (right-lateral) strike-slip fault

S-Sinistral (left-lateral) strike-slip fault

$\mathrm{N}-$ Normal fault

E-Extensional fault without vertical or strike-slip offset on one side relative to the other

U-Fault with unknown sense of slip

If the displacement is combined (i.e., oblique), separate components may be shown by:

DN-Right-lateral and normal fault

$\mathrm{D}>\mathrm{N}$-Right-lateral component is larger than the normal one

D $>N$-Right-lateral component is much larger than the normal one

D $>V$-Right-lateral component is much larger than the vertical one

$\mathrm{D} \geq \mathrm{V}$-Right-lateral component is not less than the vertical one

$\mathrm{D} / \mathrm{N}=5-10 / 1-$ Right-lateral component is 5-10 times larger than the normal one

D?-Inferred right-lateral fault, etc.

(7) Faulted layers of the lithosphere (by symbols):

S-Sedimentary cover

U-Upper part of the consolidated crust

L-Lower part of the Earth's crust

M-Mantle

If seismological, geophysical, or geochemical data on fault depth are absent, the author may include (in brackets) the results of ground observations of the fault. Symbol B is used for buried faults. Thus, fault depth (in $\mathrm{km}$ ) is shown, for example, as $\mathrm{BS}+\mathrm{U} \geq 5$ to $<20$.

$\left(8^{* *}\right) \quad$ Age of the last manifestations of fault activity. Age spans of some categories may differ from region to region (Eastern Hemisphere in parentheses and Western Hemisphere in brackets).

Q-Quaternary [1.6 Ma to present]

Q2-Middle Pleistocene $(700-100 \mathrm{ka}$ ) [730-130 ka] or younger; may subdivide into its parts (1Q2-early middle Pleistocene, 2Q2-late middle Pleistocene)

Q3-Late Pleistocene (100-10 ka) [130-10 ka] or younger; may subdivide into its parts (1Q3-early late Pleistocene, 2Q3-latest Pleistocene)

Q4-Holocene $(<10 \mathrm{ka})$ or its parts (1Q4-early Holocene, 2Q4-late Holocene)

2300 yr BP-Time of recent faulting event (typically dated by radiocarbon)

1945-Date of historic faulting event.

(9) Indications of the fault activity (by symbols):

Geological and geomorphological features that generally permit reliable delineation of active faults: 
OD-Offset or deformation of young deposits of recent motion in the deeper parts of the Earth's crust or the mantle; geodetic and historical

RG-Data from repeated geodetic measurements (including GPS)

HR-Offset of artificial or natural objects documented in historical or archaeological data

$\mathrm{VC}-$ Young volcanic features (cones, dikes, or fractures)

Other hydrothermal and hydrogeochemical indicators of suspect (inferred?) active faults:

HT-Present-day hydrothermal activity

PH-Signs of late Quaternary or Holocene hydrothermal activity

MV-Mud volcanoes and data on abnormally high pressures

GA-Recent gas and hydrogeochemical anomalies

Indirect geological evidence:

CE-Concentration of landslides and other exogenous signs of recent geodynamic activity

Remote-sensing data:

RS-Linear deformation of topography in space imagery

RM-Spectrometric anomalies interpreted as manifestations of recent geodynamic activity
Techniques of dating fault motion (and other manifestations of activity) are shown by symbols:
Ka-K-Ar

Pm-Paleomagnetic

Tc-Tephrochronological

Tm-Thermoluminescence

Tr-Tree ring studies

Lh-Lichenometric

$\mathrm{Cr}-{ }^{14} \mathrm{C}$ (radiocarbon)

In-Instrumental (geodetic or seismological)

Gc-Geological and (or) geomorphological correlation with dated formation
Ar-Archaeological

Hi-Historical

(10) Amounts of Quaternary and more recent offset, in $\mathrm{m}$. We recommend showing different components of the offset with their age and coordinates of the observed fault point or segment (the large strike-slip offset). For example:

$\mathrm{D}=250 \mathrm{~m}(\mathrm{Q}), \mathrm{R}=15 \mathrm{~m}(\mathrm{~S})$ at $\mathrm{p} 40^{\circ} 45^{\prime} 07^{\prime \prime} \mathrm{N} ., 45^{\circ} 20^{\prime} 30^{\prime \prime} \mathrm{E}$.

$\mathrm{D}=150 \mathrm{~m}(\mathrm{Q} 3+\mathrm{Q} 4), \mathrm{R}=5 \mathrm{~m}(\mathrm{~S})$ at $\mathrm{p} 40^{\circ} 45^{\prime} 07^{\prime \prime} \mathrm{N} ., 45^{\circ} 20^{\prime} 30^{\prime \prime} \mathrm{E}$.

$\mathrm{D}=150 \mathrm{~m} \& \mathrm{~V}=20 \mathrm{~m}(\mathrm{Q} 3+\mathrm{Q} 4), \mathrm{D}=20 \mathrm{~m}(\mathrm{Q} 4), \mathrm{D}=8 \mathrm{~m}$ (Q4) for s $40^{\circ} 45^{\prime} 07^{\prime \prime} \mathrm{N}$., $45^{\circ} 20^{\prime} 30^{\prime \prime}$

E. to $40^{\circ} 20^{\prime} 40^{\prime \prime}$ N., $45^{\circ} 30^{\prime} 00^{\prime \prime} \mathrm{E}$.

$\mathrm{S}=9 \mathrm{~m} \& \mathrm{~T}=1 \mathrm{~m}(\mathrm{SW}), 2300 \mathrm{yr} \mathrm{BP}$ at p $40^{\circ} 45^{\prime} 07^{\prime \prime} \mathrm{N} ., 45^{\circ} 20^{\prime} 30^{\prime \prime} \mathrm{E}$.

$\mathrm{D}=1.8 \mathrm{~m} \& \mathrm{~T}=1.2 \mathrm{~m}(\mathrm{NE}), 1948$ at $\mathrm{p} 40^{\circ} 20^{\prime} 40^{\prime \prime} \mathrm{N} ., 45^{\circ} 30^{\prime} 00^{\prime \prime} \mathrm{E}$.

(SW) means that the southwestern side of the fault is uplifted. If the vertical component is not defined, this may be the only symbol shown.

$\left(11^{* *}\right)$ Rates (velocity) of motion in $\mathrm{mm} / \mathrm{yr}$ (or $\mathrm{m} / \mathrm{ky}$ ):

$\mathrm{Vv}$-vertical

Vl-Lateral

Vs, Vd-Strike-slip

Vn-Normal

Vt-Thrust

Vr-Reverse

Ve-Extensional

Vo-Total

The rates must be related to some time interval (for example, Q4 or Q3+1Q4). 
(12) Seismic manifestations of fault zones:

Epicenters of strong earthquakes (coordinates, date, magnitude $M$ and (or) intensity I, any other focal parameters if they are important for characterizing the fault).

Seismic ruptures (coordinates of the point or the segment, date or age, length, sense and magnitude of offset).

Records of paleoseismicity with coordinates and age.

(14) Reliability of the data (A, B, or C). This somewhat subjective parameter is based on a collective appraisal of the quality, recency, and focus of the research. The following examples illustrate typical judgements of reliability:

A-Fault trace based on detailed $(<1: 50 \mathrm{M}$ scale) maps; age determinations based on radiocarbon or other numerical dating technique; slip rates based on two or more dated faulting events and well constrained amounts of offset.

B-Fault trace based on less detailed $(<1: 250 \mathrm{~K}$ scale) maps; age determinations based on numerical-dating techniques (lichenometry, paleomagnetism, etc.); slip rates based on onedated faulting event and poorly constrained amounts of offset.

C-Fault trace based on reconnaissance $(>1: 250 \mathrm{~K}$ scale) maps or photointerpretation; age determinations based on correlations or assumptions; slip rates based on inferences.

Various styles may be used to show the author(s) of the interpretation and references:

G. Smith, new data (unpublished)

G. Smith in Eaton (1984) and new data

G. Smith (1986) and new data

Eaton (1984)

If it is necessary, these abbreviated forms of references may be cited in items 1-15.

* These data need not be included by authors, because the Editorial Board can calculate them from the map. ** If these data are not available, the authors or the Editorial Board may show only the generalized ages from the inclusive categories on the map:

(8) $\mathrm{Hi}, \mathrm{Q} 4, \mathrm{Q} 3+\mathrm{Q} 4, \mathrm{Q} 2+\mathrm{Q} 3+\mathrm{Q} 4$, or $\mathrm{Q}$, and

(11) $\mathrm{V} \geq 5 \mathrm{~mm} / \mathrm{yr}, 1<\mathrm{V}<5 \mathrm{~mm} / \mathrm{yr}$ or $\mathrm{V} \leq 1 \mathrm{~mm} / \mathrm{yr}$.

Western Hemisphere data may be represented somewhat differently from Eastern Hemisphere data owing to differing levels of paleoseismic studies. This appendix is designed for well studied faults in tectonically active areas; in fact, most faults will have less than a complete listing of data. 